\title{
On-Chip Mesoporous Functionalized Magnetic Microspheres for Protein Sequencing by Extended Bottom-up Mass Spectrometry
}

\author{
Natalia Gasilova, ${ }^{\dagger}$ Kristina Srzentić, ${ }^{\dagger}$ Liang Qiao, ${ }^{\dagger}$ Baohong Liu, ${ }^{\S}$ Alain Beck, $\|$ Yury O. Tsybin, ${ }^{\perp}$ \\ and Hubert H. Girault ${ }^{*} \dagger$ \\ ${ }^{\dagger}$ Laboratory of Physical and Analytical Electrochemistry, EPFL Valais, Ecole Polytechnique Fédérale de Lausanne, 1951 Sion, Valais, \\ Switzerland \\ ${ }^{\ddagger}$ Biomolecular Mass Spectrometry Laboratory, Ecole Polytechnique Fédérale de Lausanne, 1015 Lausanne, Vaud, Switzerland \\ ${ }^{\S}$ Department of Chemistry and Institute of Biomedical Sciences, Fudan University, Shanghai 200433, PR China \\ "Centre d'Immunologie Pierre Fabre, 74160 St. Julien-en-Genevois, France \\ ${ }^{\perp}$ Spectroswiss Sàrl, EPFL Innovation Park, 1015 Lausanne, Vaud, Switzerland
}

\section{Supporting Information}

\begin{abstract}
A limited amount and extreme concentration variability of proteomic-related samples require efficient analyte preconcentration and purification prior to the mass spectrometry (MS)-based analysis. Preferably, these steps should be coupled online with chosen fractionation and detection techniques for the minimization of the sample loss. To realize such sample pretreatment, herein, an on-chip solid-phase extraction-gradient elutiontandem mass spectrometry (SPE-GEMS/MS) is introduced. This technique combines in a microfluidic format online sample preconcentration/purification on SPE sorbent with further fractionation and MS/MS analysis. $\mathrm{C}_{8^{-}}$ functionalized mesoporous magnetic microspheres are chosen as a sorbent, spatially confined with an applied magnetic field. They ensure a selective enrichment and analysis of large hydrophobic peptides $(2.5-7 \mathrm{kDa})$, matching the desired mass bin of the extended bottom-up proteomic (eBUP, 3-7 kDa)

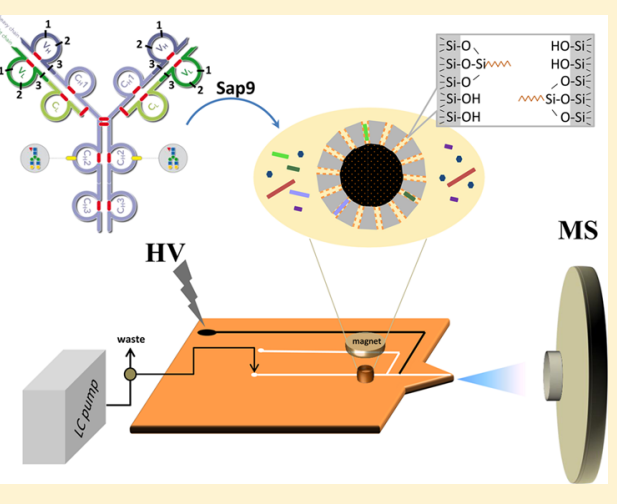
approach. Within less than $35 \mathrm{~min}$ and without additional sample purification, SPE-GEMS/MS provided $66.5 \%$ of protein sequence coverage from $75 \mathrm{fmol}$ of BSA tryptic digest. Analysis of only $33 \mathrm{fmol}$ of a single monoclonal antibody, digested with secreted aspartic protease 9 (Sap9) to large peptides, yielded $80 \%$ of its sequence coverage. A more complex equimolar mixture of six antibodies (55 fmol each), submitted to Sap9 proteolysis, was also successfully processed by SPE-GEMS/MS, resulting in 50-67\% of the total antibody sequence coverage. Importantly, for all antibodies, unique peptides containing complementarity determining regions were detected for both heavy and light chains, leading to a correct identification of mixture components despite their high sequence homology. Moreover, SPE-GEMS/MS microchip and chosen magnetic sorbent are cost-effective and can be produced and operated in a disposable manner. Therefore, the present technique could be potentially suitable for a high throughput sequencing of monoclonal antibodies and rapid eBUPbased structural protein analysis, especially when only a limited sample amount is available.
\end{abstract}

S ample enrichment and purification prior to its fractionation and detection by various separation methods coupled with mass spectrometry (MS) are the key steps for a successful proteomic experiment, especially when the limited analyte amount is available. ${ }^{1}$ In general, solid-phase extraction (SPE) is the most widely used sample enrichment method owing to its advantages, such as relatively short extraction time, reduced solvents consumption, and high preconcentration efficiency. ${ }^{2}$ Functionalized magnetic materials (FMMs) are a very attractive type of the SPE sorbents for proteomic studies. Their small size and high surface-to-volume ratio ensure high binding capacity and sensitivity of the analyte preconcentration. At the same time, the magnetic properties permit easy beads handling and manipulation by external magnetic field. The disposable manner of FMMs application as a SPE sorbent allows avoiding cross-contamination between samples and provides high assay reproducibility. ${ }^{3}$ A variety of possible functional coatings enables the extraction of peptides and proteins based on their size, amino acid content, ${ }^{2} \mathrm{~N}$-termini labeling, ${ }^{4}$ and posttranslational modifications (PTMs) like phosphorylation ${ }^{5,6}$ and glycosylation. ${ }^{7}$ Recent reviews summarize a diversity of FMMs applications for the analyte enrichment prior to the matrixassisted laser desorption/ionization (MALDI) or electrospray ionization (ESI) MS analysis not only within proteomic studies $^{2,8}$ but also for the environmental pollution monitoring, ${ }^{9,10}$ food safety, and quality control. ${ }^{3}$

Received: October 26, 2015

Accepted: December 27, 2015

Published: December 28, 2015 
For the preconcentration and general profiling of the proteome and peptidome, FMMs are mainly used with hydrophobic coatings, such as $\mathrm{C}_{8^{-}}$and $\mathrm{C}_{18^{-}}$grafted magnetic beads (MBs), ${ }^{11-13}$ which are commercially available within ready-to-use kits. ${ }^{14,15}$ Another popular type of $\mathrm{C}_{8}$-coated FMMs, not yet commercialized, is core-shell structured microspheres with standard silica shell, ${ }^{16}$ carbonaceous polysaccharide shell, ${ }^{17}$ or mesoporous silica shell $\left(\mathrm{C}_{8}-\right.$ $\left.\mathrm{Fe}_{3} \mathrm{O}_{4} @ \mathrm{mSiO}_{2}\right) .^{18,19}$

$\mathrm{C}_{8}-\mathrm{Fe}_{3} \mathrm{O}_{4} @ \mathrm{mSiO}_{2}$ microspheres with a pore size typically between 2 and $10 \mathrm{~nm}$ possess several advantages in comparison with other FMMs. These microspheres display not only hydrophobicity-dependent but also size-dependent selectivity toward target peptides. ${ }^{20}$ Only when the peptide is capable of entering the shell pore, it is retained by hydrophobic/ hydrophilic interactions with $\mathrm{C}_{8}$-coating and siloxane bridge groups. As an example, from the rat brain extract FMMs with mesopores of 3.4 and $3.7 \mathrm{~nm}$ predominantly enriched and isolated peptides within the molecular weight (MW) ranges of $1.0-2.6^{19}$ and $1.2-3.3 \mathrm{kDa},{ }^{18}$ respectively. Other advantages of $\mathrm{C}_{8}-\mathrm{Fe}_{3} \mathrm{O}_{4} @ \mathrm{mSiO}_{2}$ microspheres are an extremely large surface area and, therefore, high loading capacity, thermal and chemical stability together with high sensitivity (within picomolar range) for the peptide enrichment. ${ }^{19,20}$ Furthermore, the surface of these microspheres can be easily modified by the introduction of additional coatings, for example, metal ions $\left(\mathrm{Fe}^{3+}, \mathrm{Ce}^{4+}\right.$, $\left.\mathrm{Ga}^{3+}, \mathrm{Zr}^{4+}\right)$ and metal oxides $\left(\mathrm{TiO}_{2}, \mathrm{ZrO}_{2}, \mathrm{Al}_{2} \mathrm{O}_{3}, \mathrm{CeO}_{2}\right)$ for the selective phosphopeptide enrichment or lectin concanavalin $\mathrm{A}$ for the glycopeptides isolation. ${ }^{8,20}$

While the commercial FMMs are already used in online coupling of SPE to high-performance liquid chromatography $(\text { HPLC })^{21}$ and capillary electrophoresis, ${ }^{22,23}$ magnetic microspheres with mesoporous silica shell still remain a sorbent for the analyte extraction only in an offline mode. Moreover, their application is mainly focused on the enrichment of the sample peptidome and analyte-derived tryptic peptides ${ }^{8,19,20}$ with MWs of $1-3 \mathrm{kDa}$, characteristic for bottom-up proteomics (BUP). ${ }^{24}$ However, $\mathrm{C}_{8}-\mathrm{Fe}_{3} \mathrm{O}_{4} @ \mathrm{mSiO}_{2}$ microspheres were already demonstrated to empower the isolation of larger endogenous peptides (up to $5 \mathrm{kDa}$ ) from human blood serum. ${ }^{18}$ Such property indicates the potential suitability of this FMM for the extended bottom-up proteomics (eBUP), which deals with the 3-7 kDa peptides. ${ }^{24}$ In contrast with classical BUP approach, eBUP gives an improved sequence coverage and PTMs analysis due to the reduced sample complexity and higher information density obtained from large unique peptides. ${ }^{24,25}$ Therefore, enrichment of the eBUP samples with porous FMMs followed by MS analysis, especially realized in an online format, could become a new promising strategy for protein structural analysis and proteomic studies.

Herein, $\mathrm{C}_{8}-\mathrm{Fe}_{3} \mathrm{O}_{4} @ \mathrm{mSiO}_{2}$ microspheres are introduced as a sorbent for on-chip solid-phase extraction-gradient elutiontandem mass spectrometry (SPE-GEMS/MS) for eBUP-based protein structural analysis. This microfluidics-based technique is shown to enable subsequent analyte preconcentration, purification, fractionation, and online MS/MS analysis. Improved microchip design ${ }^{26}$ with linear elution gradient, created by external LC pump, and porous FMM as SPE sorbent ensure fast, sensitive, and efficient analysis of large peptides $(2.5-7 \mathrm{kDa})$. Femtomolar sample quantities can be easily processed with this approach as was demonstrated in proof-ofconcept experiments realized with BSA tryptic digest. The analytical performance of the SPE-GEMS/MS technique for
eBUP samples was further evaluated by the analysis of a single monoclonal IgG antibody, directly after digestion with secreted aspartic protease 9 (Sap9) from C. albicans ${ }^{27}$ using the protocol specially tailored for eBUP. ${ }^{25}$ A mixture of monoclonal antibodies, IgGs, submitted to Sap9 proteolysis, was also successfully processed on a SPE-GEMS/MS microchip illustrating the potential suitability of the proposed strategy for rapid primary structure assessment of therapeutic antibodies from a limited sample amount.

\section{EXPERIMENTAL SECTION}

Chemicals and Materials. Trastuzumab (Herceptin, IgG1, Genentech), Adalimumab (Humira, IgG1, Abbott Laboratories), Bevacizumab (Avastin, IgG1, Genentech/Roche), Rituximab (Rituxan, IgG1, IDEC Pharmaceuticals/Genentech), Panitumumab (Vectibix, IgG2, Amgen), and Natalizumab (Antegren, IgG4, Biogen IDEC) were obtained in their formulation buffers. $\mathrm{C}_{8}$-coated superparamagnetic beads (1.08 $\mu \mathrm{m}$ diameter) were purchased from Bioclone Inc. (San Diego, CA, USA). Insulin chain B oxidized (from bovine pancreas), bradykinin (acetate salt, $\geq 98 \%$ ), BSA (98\%), and iodoacetamide (IAA, 97\%) were obtained from Sigma-Aldrich (Buchs, Switzerland). Angiotensin I (trifluoroacetate salt, 98\%) was purchased from Bachem (Dübendorf, Switzerland). ACTH human (1-24) was obtained from Anaspec (Fremont, CA, USA). Trypsin (from bovine pancreas) was purchased from Applichem (Darmstadt, Germany). Acetic acid (99.5\%), trifluoroacetic acid (TFA), ammonium bicarbonate (99.5\%), and 1,4-dithiothreitol $(\geq 99 \%)$ were purchased from Fluka (Buchs, Switzerland). Methanol (>99\%) was obtained from Merck (Darmstadt, Germany). For sample solutions and all experiments, deionized water produced by an alpha Q-Millipore System (Zug, Switzerland) was used.

$\mathrm{C}_{8}-\mathrm{Fe}_{3} \mathrm{O}_{4} @ \mathrm{mSiO}_{2}$ Microspheres Characterization. $\mathrm{C}_{8}-$ $\mathrm{Fe}_{3} \mathrm{O}_{4} @ \mathrm{mSiO}_{2}$ microspheres (300-350 nm in diameter) were synthesized using one-pot sol-gel coating strategy as described elsewhere. ${ }^{19}$ The structure of the $\mathrm{C}_{8}-\mathrm{Fe}_{3} \mathrm{O}_{4} @ \mathrm{mSiO}_{2}$ microspheres was further analyzed by high resolution scanning electron microscopy (HR-SEM) and transmission electron microscopy (TEM). HR-SEM images were recorded with a SEM Merlin instrument from Zeiss (Jena, Germany), using a Gemini II column (Shottky emission) and an inlet secondary electron detector. The sample was prepared by deposition of its powder on a conducting carbon tape with an aluminum support.

TEM images were taken with a Philips/FEI CM12 microscope (Eindhoven, Netherlands). A $\mathrm{LaB}_{6}$ source was used at an operating voltage of $120 \mathrm{kV}$, and micrographs were recorded with Gatan $1024 \times 1024$ pixels MultiScan CCD camera (Warrendale, PA, USA), while data were processed and analyzed with Gatan DigitalMicrograph 3.4 software. The samples were prepared by dispersion in ethanol and deposition on a carbon film with a 200 mesh copper grid CF200-Cu from Electron Microscopy Sciences (Hatfield, PA, USA).

BSA Tryptic Digestion. BSA $(5 \mathrm{mg} / \mathrm{mL})$ in $100 \mathrm{mM}$ ammonium bicarbonate buffer $(\mathrm{pH} 7.8)$ was reduced by adding $200 \mathrm{mM}$ 1,4-dithiothreitol (DTT) in $50 \mathrm{mM}$ Tris-HCl buffer $(\mathrm{pH} 8)$ to a final DTT concentration of $10 \mathrm{mM}$. The obtained solution was incubated for $5 \mathrm{~min}$ at $95{ }^{\circ} \mathrm{C}$. Then, it was alkylated by mixing with $200 \mathrm{mM}$ iodoacetamide (IAA) in 50 $\mathrm{mM}$ Tris-HCl buffer $(\mathrm{pH} 8)$ to a final IAA concentration of 18 $\mathrm{mM}$ and incubated for $20 \mathrm{~min}$ at room temperature in the dark. Trypsin from bovine pancreas $(0.5 \mathrm{mg} / \mathrm{mL}$ in water) was finally 
a)

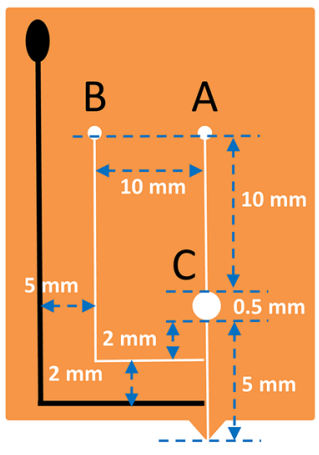

b)

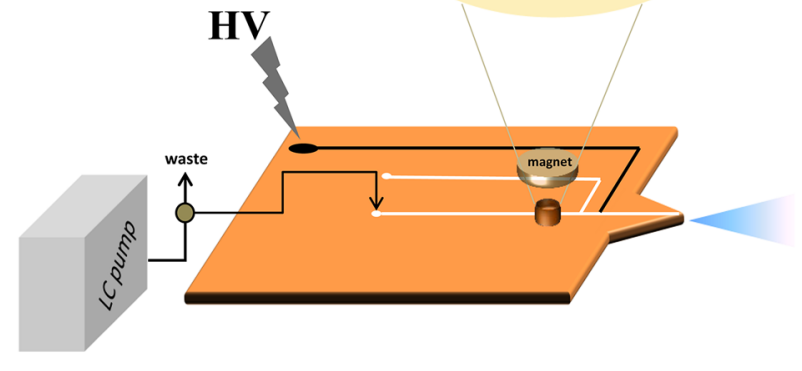

MS

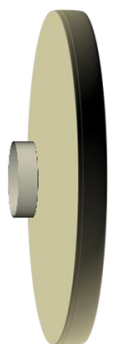

Figure 1. a) SPE-GEMS/MS microchip design; carbon microelectrode (black line) and microchannels (white lines): A - main, B - sheath-flow, and $\mathrm{C}$ - trapping chamber for the magnetic SPE sorbent. b) Schematic representation of the experimental setup. For the electrospray induction, high voltage (HV) is applied to the SPE-GEMS/MS microchip emitter, placed in front of the ion transfer capillary inlet of MS instrument. Meanwhile, for the fractionation of the analyte, enriched on the magnetic SPE sorbent, the eluent flow and composition are controlled by analytical LC pump and microsplitter valve.

added in a ratio of $1: 30(\mathrm{w} / \mathrm{w}$, enzyme/protein), and the reaction mixture was incubated overnight at $37{ }^{\circ} \mathrm{C}$. The reaction was quenched by freezing the digest solution for storage at $-20{ }^{\circ} \mathrm{C}$.

Sap9 Proteolysis of Monoclonal Antibodies. Sap9 from $C$. albicans was recombinantly expressed in P. pastoris and purified as previously described. ${ }^{28}$ This enzyme is commercially available from Spectroswiss (Lausanne, Switzerland). Prior to the proteolysis, $10 \mu \mathrm{g}$ of single monoclonal IgG antibody Trastuzumab, present initially in the formulation buffer, was diluted 10 times with $6.8 \mathrm{M}$ urea in $100 \mathrm{mM}$ ammonium bicarbonate buffer ( $\mathrm{pH} 7.8$ ), mixed with $100 \mathrm{mM}$ DTT in water to a final DTT concentration of $5 \mathrm{mM}$ and incubated for $1 \mathrm{~h}$ at $50{ }^{\circ} \mathrm{C}$. Then, $100 \mathrm{mM}$ IAA in water was added to its final concentration of $18 \mathrm{mM}$, and the reaction mixture was incubated for $45 \mathrm{~min}$ at room temperature in the dark. After the alkylation, the sample solution was diluted 20 times with 50 $\mathrm{mM}$ sodium citrate buffer ( $\mathrm{pH}$ 5.5), mixed with Sap9 in a 1:10 ratio (w/w, enzyme/protein), and incubated for $1 \mathrm{~h}$ at room temperature. The reaction was quenched by adding TFA to its final concentration of $1 \%$, and the digest was ready to be analyzed by SPE-GEMS/MS without any additional purification steps. An equimolar mixture of six monoclonal IgGs consisting of Trastuzumab, Adalimumab, Bevacizumab, Rituximab, Panitumumab, and Natalizumab was submitted to the reduction, alkylation, and proteolysis with Sap9 following the same protocol as was described for the single antibody.

SPE-GEMS/MS Experiment. A SPE-GEMS/MS microchip was designed as shown in Figure $1 \mathrm{a}$ and fabricated from a polyimide (PI) substrate (125 $\mu \mathrm{m}$ thick, DuPontKapton polyimide film, Dupont, Geneva, Switzerland) by scanning laser ablation as previously reported. ${ }^{26}$

A detailed description of the microchip fabrication is presented in Supporting Information (SI) section SI-1. After the fabrication, the microchip was inserted into a homemade plastic holder with tight fittings (IDEX Health and Science LLC, Oak Harbor, WA, USA). The solution delivery into the device was realized via fused silica capillaries $(75 \mu \mathrm{m}$ i.d, 360 $\mu \mathrm{m}$ o.d., BGB analytik AG, Böckten, Switzerland) either by a syringe pump (KD Scientific, Holliston, MA, USA) or an analytical LC pump (Accela, Thermo Scientific, San Jose, CA, USA).

In a typical SPE-GEMS/MS experiment, $\mathrm{C}_{8}-\mathrm{Fe}_{3} \mathrm{O}_{4} @ \mathrm{mSiO}_{2}$ microspheres $(10 \mu \mathrm{L}, 5 \mathrm{mg} / \mathrm{mL}$ in $0.1 \%$ TFA water solution) were loaded into the microchip chamber, where they were retained externally by four permanent magnets $(\mathrm{Nd}-\mathrm{Fe}-\mathrm{B}, 1$ $\mathrm{mm}$ diameter, $1 \mathrm{~mm}$ height, N45, Supermagnete, Zürich, Switzerland) placed two above and below the chamber. Ten $\mu \mathrm{L}$ of the sample, previously diluted in $0.1 \%$ TFA water solution, was, then, introduced into the microchip, followed by washing with $15 \mu \mathrm{L}$ of $0.1 \%$ TFA water solution. Loading of the magnetic sorbent and sample solutions, as well as the washing step, was realized via the microchannel A by a syringe pump at a flow rate of $1 \mu \mathrm{L} / \mathrm{min}$. Meanwhile, the inlet of the sheath-flow microchannel B was blocked by a blind tight fitting to prevent the liquid from entering into this channel.

After the washing step, elution of the enriched analyte from $\mathrm{C}_{8}-\mathrm{Fe}_{3} \mathrm{O}_{4} @ \mathrm{mSiO}_{2}$ microspheres was realized with an eluent flow of $50 \mu \mathrm{L} / \mathrm{min}$ created by the LC pump. Prior to the injection into the microchannel $\mathrm{A}$, the eluent flow rate was decreased from 50 to $1 \mu \mathrm{L} / \mathrm{min}$ by a flow splitter valve (IDEX Health and Science LLC, Oak Harbor, WA, USA) ensuring the correct device performance without a risk of its delamination. The eluent composition was controlled by Xcalibur software (Thermo Scientific, San Jose, CA, USA). Solvent A consisted of $0.1 \%$ TFA in water and solvent B of $0.1 \%$ TFA in methanol. The solvent B percentage was increased linearly within $20 \mathrm{~min}$ from 5 to $50 \%$ and from 10 to $70 \%$, for the analysis of BSA and IgGs digests, respectively. A voltage of $3.8 \mathrm{kV}$ was applied to the microchip electrode inducing the electrospray from the microchip emitter, placed in front of the ion transfer capillary inlet of a linear ion trap LTQ Velos mass spectrometer (Thermo Scientific, San Jose, CA, USA), as schematically shown in Figure $1 \mathrm{~b}$. At the same time, the ESI solution consisting of $70 \%$ methanol and $1 \%$ acetic acid in water was injected as a sheath-flow via microchannel $B$ at a flow rate of $0.17 \mu \mathrm{L} / \mathrm{min}$ to assist the electrospray formation if needed. Otherwise, this microchannel inlet was blocked with the blind tight fitting.

Survey and data-dependent MS/MS scans were acquired in a positive ion mode with a scan rate of $10000 \mathrm{Th} / \mathrm{s}$ (enhanced 
mode) and automatic gain control (AGC) set at 3E4 and 1E4, respectively. Respecting the width of the eluting SPE-GEMS/ MS fractions, the dynamic exclusion duration for the precursor ions was set to $10 \mathrm{~s}$ with single repeat count duration. The precursor ion isolation width was fixed to $2.5 \mathrm{Th}$. Collisioninduced dissociation (CID) was used for the isolated precursor ion fragmentation with the normalized collision energy (NCE) of $35 \%$ with $3+$ as a default charge state. The minimum signal threshold for triggering MS/MS was fixed at 5000 counts, and active rejection of singly charged species was enabled. All the SPE-GEMS/MS experiments were repeated in triplicates.

Raw data were processed with open Trans-Proteomic Pipeline software (TPP, Institute for Systems Biology, Seattle Proteome Center). ${ }^{29}$ The cleavage specificity for trypsin was set with two allowed missed cleavages, while for Sap9 the same cleavage specificity as for trypsin was used with eight allowed missed cleavages, in both cases with semispecific cleavage accepted. The precursor and product ion mass tolerances were set to 0.55 and $0.4 \mathrm{Da}$, respectively. BSA and IgGs peptides were searched against the custom databases containing BSA and six IgGs sequences, respectively. Cysteine residue carbamidomethylation, methionine residue oxidation, and $\mathrm{N}$ terminal pyroglutamic acid formation from glutamine residue were chosen as dynamic modifications. The false discovery error rate for TPP software was set to $2.5 \%$ with a minimal peptide length of seven amino acids.

\section{RESULTS AND DISCUSSION}

SPE-GEMS/MS: Microchip Design and Protocol Optimization. The structure of the $\mathrm{C}_{8}-\mathrm{Fe}_{3} \mathrm{O}_{4} @ \mathrm{mSiO}_{2}$ microspheres with a total diameter of 300-350 nm was verified by HR-SEM and TEM imaging (SI-2 section). The magnetic core composed of the $\mathrm{Fe}_{3} \mathrm{O}_{4}$ was clearly observed from the HR-SEM (Figure SI-2a) and TEM images (Figure SI-2c), as well as the porous structure of the $\mathrm{C}_{8}$-modified silica shell (thickness of $\sim 20-25 \mathrm{~nm}$ ) with $\sim 4.0 \mathrm{~nm}$ pore size (Figure SI-2b and d).

In contrast with the previously described microfluidic device, ${ }^{26}$ the amount of the $\mathrm{C}_{8}-\mathrm{Fe}_{3} \mathrm{O}_{4} @ \mathrm{mSiO}_{2}$ microspheres loaded into the SPE sorbent chamber was increased up to $50 \mu \mathrm{g}$ to improve the sample loading capacity. Moreover, the overall microchip design was simplified for SPE-GEMS/MS analysis as shown in Figure 1a, which was feasible as the LC pump and splitter valve were integrated for the control of the eluent flow rate and composition. The working flow rate of $1 \mu \mathrm{L} / \mathrm{min}$ was chosen to ensure stable spray from the microchip emitter. It is worth mentioning that the created plug of $\mathrm{C}_{8}-\mathrm{Fe}_{3} \mathrm{O}_{4} @ \mathrm{mSiO}_{2}$ microspheres could withstand the flow rate up to $2-2.5 \mu \mathrm{L} /$ min, while the microchip lamination typically resisted the flow rate up to $3-3.3 \mu \mathrm{L} / \mathrm{min}$.

The distance between the SPE sorbent chamber and junction of the microchannels $A$ and $B$ was further decreased to $2 \mathrm{~mm}$ in comparison with previous design, ${ }^{26}$ while the distance between the electrode and the microchip tip was shortened to $1 \mathrm{~mm}$. Such modifications reduced the broadening of the peptide bands eluted from $\mathrm{C}_{8}-\mathrm{Fe}_{3} \mathrm{O}_{4} @ \mathrm{mSiO}_{2}$ microspheres caused by diffusion/convection processes within the laminar flow inside the microchannel. A further decrease of these parameters was limited by the risk of the microchip delamination. The size of the chamber for SPE sorbent was kept at $500 \mu \mathrm{m}$ in diameter. The volume of the sample injected into the microchip was set to $10 \mu \mathrm{L}$ providing sample loading time of $10 \mathrm{~min}$. The elution gradient program was adjusted according to the type of the sample submitted to SPE-GEMS/MS analysis. The duration of the elution gradient and MS analysis was always fixed to 20 $\min$.

As was demonstrated previously, ${ }^{26}$ in such systems like the SPE-GEMS/MS microchip, the sample elution from the small plug of the magnetic SPE sorbent typically creates very narrow and concentrated analyte bands. These bands are further subjected to the broadening, while passing to the microchip tip and result in peaks width of $1-5$ s. To guarantee a good balance between the sensitivity and duty cycle length, crucial for a successful MS analysis of these narrow analyte fractions, the AGC values for survey and MS/MS scans were kept at the standard settings for the LTQ Velos instrument. ${ }^{30}$ It allowed 2-10 MS/MS scans per SPE-GEMS/MS fraction peak, while using an enhanced mode with a scan rate of $10000 \mathrm{Th} / \mathrm{s}$ to achieve improved MS resolution.

To roughly estimate the preconcentration efficiency achievable with new mesoporous SPE sorbent in comparison with the commercial nonporous $\mathrm{C}_{8}$-coated magnetic beads, a model equimolar mixture of peptides angiotensin $\mathrm{I}$, human ACTH (1-24), and insulin chain B oxidized was analyzed by SPE-GEMS/MS with both types of magnetic sorbent. The obtained limit of detection (LOD), limit of quantification (LOQ), linear dynamic range (LDR), and enrichment factor (EF) values for SPE-GEMS/MS analysis in comparison with a direct sample injection via a plain microchip emitter (without SPE sorbent loaded) are displayed in Table SI-3. The formulas used to calculate LODs, LOQs, and EFs are also explained in SI-3 section.

Angiotensin I, as the smallest relatively hydrophobic peptide in the mixture, was eluted first during the fractionation step of SPE-GEMS/MS analysis using $\mathrm{C}_{8}-\mathrm{Fe}_{3} \mathrm{O}_{4} @ \mathrm{mSiO}_{2}$ microspheres. Its LOD was defined as $50 \mathrm{fmol}$ for $10 \mu \mathrm{L}$ of the loaded sample with an EF value of 50. Meanwhile, for such large peptides as insulin chain B and ACTH human (1-24), it was possible to detect as low as $10 \mathrm{fmol}$ for the same amount of the injected sample. In contrast, during the SPE-GEMS/MS analysis using commercial $\mathrm{C}_{8}$-coated magnetic beads, the peptide elution order was different. ACTH human (1-24), being a large, but relatively hydrophilic peptide, was eluted first with the highest LOD of $500 \mathrm{fmol}$. It was followed by short relatively hydrophobic angiotensin I, that was well retained on this sorbent demonstrating an LOD of $250 \mathrm{fmol}$. Insulin chain $B$ was eluted last with the lowest LOD of $100 \mathrm{fmol}$ due to its high hydrophobicity. As was expected, commercial $\mathrm{C}_{8}$-coated magnetic beads demonstrated only hydrophobicity-dependent selectivity, while $\mathrm{C}_{8}-\mathrm{Fe}_{3} \mathrm{O}_{4} @ \mathrm{mSiO}_{2}$ microspheres displayed also size-dependent selectivity. Moreover, standard magnetic sorbent demonstrated a lower loading capacity, 5 to 50 times higher LOD and LOQ values for all the components of the peptide mixture in comparison with the mesoporous sorbent. Higher affinity of the model peptides toward $\mathrm{C}_{8}-\mathrm{Fe}_{3} \mathrm{O}_{4} @$ $\mathrm{mSiO}_{2}$ microspheres also determined their significantly higher EF values, calculated as 200-240. The described gain in detection sensitivity, provided by the SPE-GEMS/MS technique with the mesoporous magnetic sorbent, enables the analysis of very small analyte quantities in a rapid and effective manner, as demonstrated below on more complex samples.

Analysis of BSA Tryptic Digest. As a proof-of-concept, SPE-GEMS/MS analysis with $\mathrm{C}_{8}-\mathrm{Fe}_{3} \mathrm{O}_{4} @ \mathrm{mSiO}_{2}$ microspheres was, first, performed with BSA tryptic digest. To compare this porous FMM with a conventional nonporous one, the same samples were also processed by SPE-GEMS/MS with commercial $\mathrm{C}_{8}$-coated magnetic beads as a sorbent. The BSA 
Table 1. SPE-GEMS/MS Analysis of BSA Tryptic Digest ${ }^{c}$

\begin{tabular}{|c|c|c|c|c|c|c|}
\hline \multirow[b]{2}{*}{ magnetic sorbent } & \multirow[b]{2}{*}{ analyte amount, ng/fmol } & \multicolumn{2}{|c|}{$\begin{array}{c}\text { identified } \\
\text { peptides, } \#^{a}\end{array}$} & \multirow[b]{2}{*}{ BSA sequence coverage, $\%$} & \multirow[b]{2}{*}{ peptide average $\mathrm{MW}, \mathrm{kDa}$} & \multirow[b]{2}{*}{ peptide $\mathrm{MW}$ range, $\mathrm{kDa}$} \\
\hline & & total $^{a}$ & $\min ^{b}$ & & & \\
\hline \multirow{3}{*}{$\mathrm{C}_{8}-\mathrm{Fe}_{3} \mathrm{O}_{4} @ \mathrm{mSiO}_{2}$} & $250 / 3750$ & 170 & 26 & 88 & 2.4 & $1.1-4.2$ \\
\hline & $50 / 750$ & 157 & 23 & 84 & 2.9 & $2.2-5.1$ \\
\hline & $5 / 75$ & 57 & 15 & 66.5 & 2.7 & $2.2-3.9$ \\
\hline \multirow[t]{3}{*}{$\mathrm{C}_{8}$-coated $\mathrm{MBs}$} & $250 / 3750$ & 27 & 15 & 45 & 2.1 & $1.1-3.6$ \\
\hline & $50 / 750$ & 30 & 21 & 50 & 1.8 & $1.1-3.3$ \\
\hline & $5 / 75$ & 26 & 8 & 42 & 1.9 & $1.1-2.8$ \\
\hline
\end{tabular}

${ }^{a}$ All identified peptides (including the ones carrying various modifications). ${ }^{b}$ Minimum number of peptides required to achieve the corresponding sequence coverage. ${ }^{c} \mathrm{MW}-$ molecular weight.
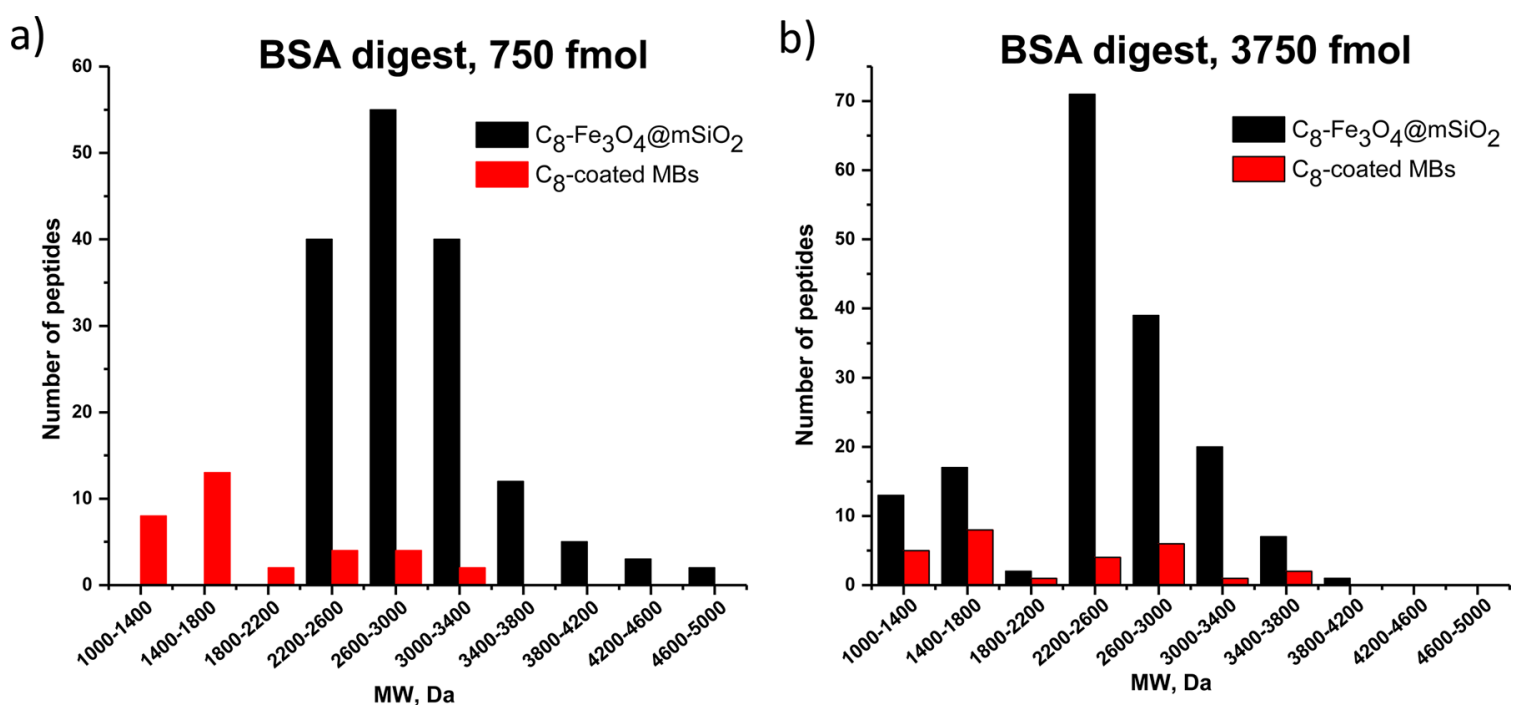

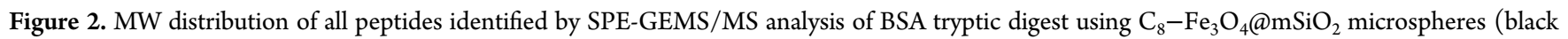
bars) and commercial $\mathrm{C}_{8}$-coated MBs (red bars). Loaded sample amount: a) $750 \mathrm{fmol}(50 \mathrm{ng})$ and $3750 \mathrm{fmol}(250 \mathrm{ng})$.

digest was analyzed at concentrations of $0.5,5$, and $25 \mu \mathrm{g} / \mathrm{mL}$, corresponding to 75,750 , and $3750 \mathrm{fmol}$ of the sample injected into the microchip, respectively. SPE-GEMS/MS data acquired with both types of SPE sorbent are summarized in Table 1. Peptides identified from $75 \mathrm{fmol}$ of the BSA digest are listed in the SI-4 section.

As can be concluded from the displayed results (Tables 1, SI4.1, and 4.2) $\mathrm{C}_{8}-\mathrm{Fe}_{3} \mathrm{O}_{4} @ \mathrm{mSiO}_{2}$ microspheres are significantly better and more effective for the peptide enrichment than the commercial $\mathrm{C}_{8}$-coated $\mathrm{MBs}$ under the same experimental conditions applied. From only 75 fmol of injected sample, SPEGEMS/MS analysis with porous FMM provided $66.5 \%$ of BSA sequence coverage from 57 enriched peptides. For the same analyte amount, application of $\mathrm{C}_{8}$-coated $\mathrm{MBs}$ as the SPE sorbent yielded only $42 \%$ of protein sequence coverage from only 26 identified peptides. Increasing the amount of the loaded sample 10 and 50 times almost did not increase the total number of detected peptides, indicating the saturation of the $\mathrm{C}_{8}$-coated MBs-based plug already with $75 \mathrm{fmol}$ of injected BSA digest. In contrast, porous $\mathrm{C}_{8}-\mathrm{Fe}_{3} \mathrm{O}_{4} @ \mathrm{mSiO}_{2}$ microspheres possess a much larger specific surface area, i.e. higher loading capacity, estimated to be $\sim 50-60 \mathrm{ng}$ of protein digest per on-chip SPE plug (Table 1). Hence, from $750 \mathrm{fmol}$ of the sample they enriched 6 times more peptides including the modified ones (Table SI-4), enabling PTMs analysis without fast sorbent saturation. Meanwhile, 1.7 times higher BSA sequence coverage was achieved from the same minimum number of peptides, as this FMM preferably preconcentrates larger peptides within a broader MW range than the commercial $\mathrm{C}_{8}$-coated MBs (Table 1 and Figure 2). Larger peptides carried a higher density of protein sequence information providing improved sequence coverage from the same sample amount.

SPE-GEMS/MS analysis with $\mathrm{C}_{8}-\mathrm{Fe}_{3} \mathrm{O}_{4} @ \mathrm{mSiO}_{2}$ microspheres mainly identified large and relatively hydrophobic peptides in the MW range of $2.2-3.4 \mathrm{kDa}$ (Figure 2, black bars), confirming size-dependent selectivity of the chosen sorbent because of its mesopores. ${ }^{20}$ Despite the low abundance of peptides larger than $3 \mathrm{kDa}$ in the protein digests generated by trypsin, peptides with $\mathrm{MW}$ up to $5.1 \mathrm{kDa}$ were easily detected by the proposed on-chip technique with the mesoporous FMM. When a large sample amount of 3750 fmol (250 ng) was loaded inside the SPE-GEMS/MS microchip (Figure 2b, black bars), $\mathrm{C}_{8}-\mathrm{Fe}_{3} \mathrm{O}_{4} @ \mathrm{mSiO}_{2}$ microspheres also enriched some smaller peptides in the MW range of $1-1.8 \mathrm{kDa}$. It occurred owing to the high concentration of the sample loaded and high abundance of such peptides in it. In the case of commercial $\mathrm{C}_{8}$-coated MBs (Figure 2, red bars), the difference in the peptide MW ranges for concentrated or diluted samples was almost negligible, being a consequence of the fast sorbent saturation.

Furthermore, the combination of SPE-GEMS/MS analysis with $\mathrm{C}_{8}-\mathrm{Fe}_{3} \mathrm{O}_{4} @ \mathrm{mSiO}_{2}$ microspheres provided better results in BSA digest analysis than other reported techniques involving 
Table 2. SPE-GEMS/MS Analysis of Trastuzumab Digested with Sap9 ${ }^{c}$

\begin{tabular}{|c|c|c|c|c|c|c|c|c|}
\hline \multirow[b]{3}{*}{ sample amount, $\mathrm{ng} / \mathrm{fmol}$} & \multicolumn{4}{|c|}{ identified peptides, $\#^{a}$} & & & \multirow[b]{3}{*}{ peptide average $\mathrm{MW}, \mathrm{kDa}$} & \multirow[b]{3}{*}{ peptide $\mathrm{MW}$ range, $\mathrm{kDa}$} \\
\hline & \multicolumn{2}{|c|}{$\mathrm{Hc}$} & \multicolumn{2}{|c|}{$\mathrm{Lc}$} & \multicolumn{2}{|c|}{ sequence coverage, $\%$} & & \\
\hline & $\operatorname{total}^{a}$ & $\min ^{b}$ & total $^{a}$ & $\min ^{b}$ & $\mathrm{Hc}$ & $\overline{\mathrm{Lc}}$ & & \\
\hline $125 / 833$ & 157 & 14 & 56 & 7 & 99 & 100 & 3.5 & $2.7-5.4$ \\
\hline $50 / 333$ & 179 & 14 & 50 & 7 & 98.5 & 99 & 3.7 & $2.7-7.5$ \\
\hline $5 / 33$ & 53 & 13 & 15 & 5 & 80 & 80 & 3.4 & $2.4-6.5$ \\
\hline
\end{tabular}

${ }^{a}$ All identified peptides including the ones carrying various modifications. ${ }^{b}$ Minimum number of peptides required to achieve the corresponding sequence coverage. ${ }^{c} \mathrm{Hc}$ - heavy chain; Lc - light chain; MW - molecular weight.
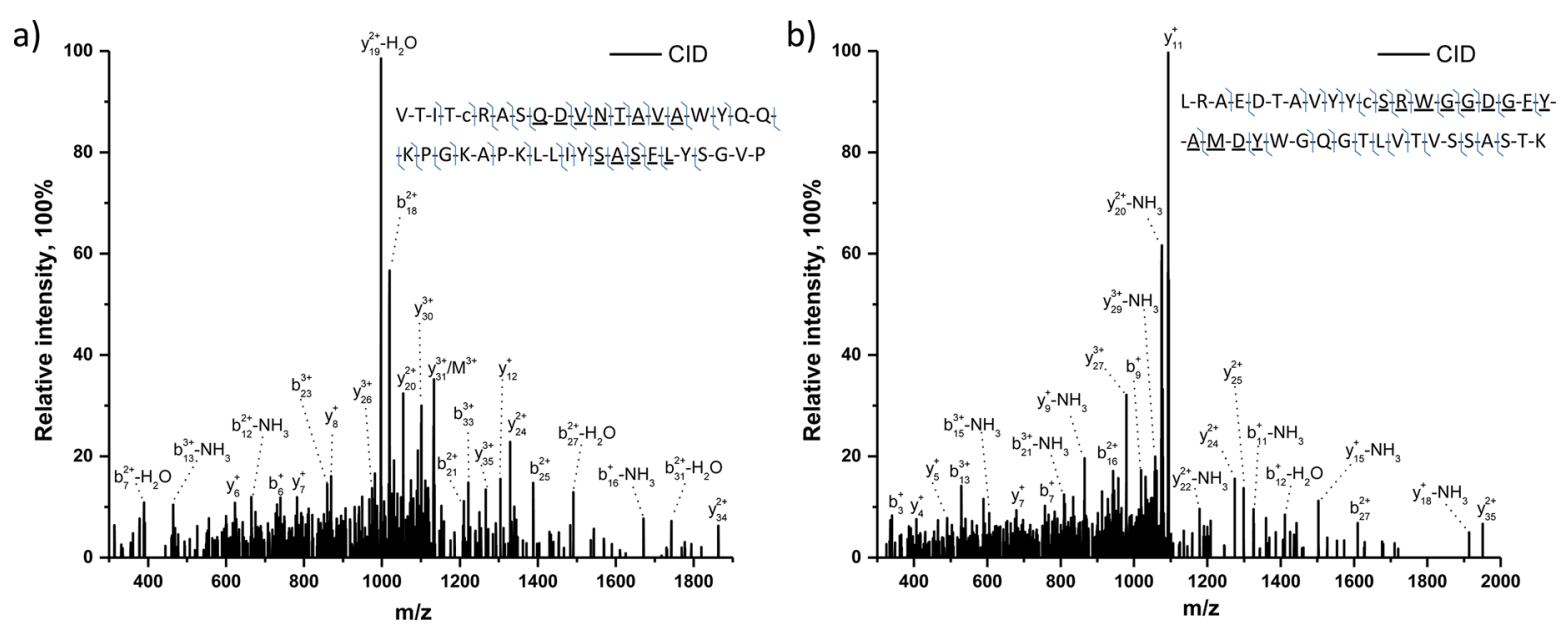

Figure 3. Representative CID mass spectra of CDR-containing peptides with assignments of their respective $b, y$ product ions, identified by SPEGEMS/MS analysis of single therapeutic monoclonal antibody Trastuzumab (IgG1) digested with Sap9. Selected peptides derived from a) Lc, with CDRs 1 and 2, MW = 4527.4 Da; b) Hc, with CDR 3, MW = 4367.9 Da. Insets: corresponding peptide sequences with assigned peptide backbone cleavage sites and underlined CDRs. Experimental conditions: $\mathrm{C}_{8}-\mathrm{Fe}_{3} \mathrm{O}_{4} @ \mathrm{mSiO}_{2}$ microspheres as a SPE sorbent, $333 \mathrm{fmol}$ (50 ng) of loaded sample.

mesoporous FMMs. ${ }^{8}$ For example, the use of $50 \mu \mathrm{g}$ of FMM with plain silica mesopores of 2 nm size $\left(\mathrm{Fe}_{3} \mathrm{O}_{4} @ \mathrm{nSiO} \mathrm{O}_{2} @\right.$ $\mathrm{mSiO}_{2}$ microspheres) for the in-tube enrichment of $1.3 \mu \mathrm{g}$ of BSA digest yielded only in $32 \%$ of BSA sequence coverage (21 identified peptides) with MALDI-MS analysis. ${ }^{31}$ Similar data were obtained for the $\mathrm{C}_{8}-\mathrm{Fe}_{3} \mathrm{O}_{4} @ \mathrm{mSiO}_{2}$ microspheres. ${ }^{19}$ The application of $200 \mu \mathrm{g}$ of $\mathrm{Fe}_{3} \mathrm{O}_{4} \mathrm{nSiO}_{2}$ meso-hybrid- $\mathrm{C}_{8}$ microspheres for the preconcentration of $167 \mu \mathrm{g}$ of BSA digest led to the detection of only 13 to 26 peptides by MALDI-MS. ${ }^{18} \mathrm{~A}$ potential explanation for the low sample recovery in spite of the application of such powerful FMMs is the realization of the enrichment/detection procedure in the offline mode and without the separation of the extracted peptides prior to MS analysis. The SPE-GEMS/MS technique overcomes these limitations and offers better sensitivity and efficiency, while requiring smaller sample amounts.

For the analysis of the single protein digest, the SPE-GEMS/ MS technique could be advantageous also in comparison with standard nano HPLC-MS ${ }^{32-35}$ or even UPLC-MS ${ }^{35-37}$-based proteomic methods, as it provides at least 2-3 times faster experimental performance. The small size of the SPE plug in the SPE-GEMS/MS microchip results in the plug regeneration and equilibration time of only 1-2 min. Moreover, upon the magnet removal the SPE plug can be flushed away and easily renewed by loading a new portion of $\mathrm{C}_{8}-\mathrm{Fe}_{3} \mathrm{O}_{4} @ \mathrm{mSiO}_{2}$ microspheres, to avoid completely the cross-contamination between different samples. In the meantime, the quantity of BSA tryptic digest used by SPE-GEMS/MS can be 1.5 times higher, $^{32}$ comparable $^{35}$ or even lower ${ }^{33,37}$ than the one required by nano LC-MS methods to reach the same protein sequence coverage.

Analysis of Trastuzumab Digested with Sap9. As the SPE-GEMS/MS technique with $\mathrm{C}_{8}-\mathrm{Fe}_{3} \mathrm{O}_{4} @ \mathrm{mSiO}_{2}$ microspheres was efficient for the preconcentration and identification of large peptides, it could be suitable for the analysis of the proteomic samples digested with Sap9. This recombinant protease, specially selected for eBUP experiments, produces in comparison with trypsin larger peptides with average MW of $3.5 \mathrm{kDa}^{25}$ It was successfully applied for the digestion of therapeutic monoclonal IgGs prior to their analysis by reversedphase nano HPLC coupled with high resolution MS. ${ }^{27}$ Such an approach provided from 8 pmol of injected sample up to $100 \%$ IgG sequence coverage together with the detection of connectivity between complementarity determining regions (CDRs, i.e. antigen recognition and binding domains) due to the large size of the peptides generated by Sap9. Therefore, the same type of samples was chosen for further SPE-GEMS/MS experiments aiming for the fast antibody identification from the low sample amount.

Sap9-derived digest of therapeutic monoclonal antibody, Trastuzumab IgG1, was analyzed at concentrations of $0.5,5$, and $12.5 \mu \mathrm{g} / \mathrm{mL}$, corresponding to 33,333 , and $833 \mathrm{fmol}$ of the sample injected into the microchip, respectively. No additional sample pretreatment prior to the SPE-GEMS/MS analysis was applied in contrast with the nano HPLC-based method, where the digest was purified with pooled $\mathrm{C} 4$ and $\mathrm{C} 18$ Zip-Tip cartridges. ${ }^{27}$ The elution gradient was modified in order to guarantee the elution of all large peptides trapped on porous 
FMM sorbent and consisted of the linear increase of the solvent B content from 10 to $70 \%$. As Sap9 typically cleaves in the vicinity of dibasic residues and in the select cases also at basic and hydrophobic residues, ${ }^{25}$ the cleavage rules set for Sap9 during the database search with TPP were the same as for trypsin, but allowing eight missed cleavages (see the Experimental Section). The results are presented in Table 2, while a list of peptides, identified from $33 \mathrm{fmol}$ of the loaded Trastuzumab digest, is demonstrated in the SI-5 section.

As was expected, with the Sap9 proteolysis the average MW of the peptides enriched by $\mathrm{C}_{8}-\mathrm{Fe}_{3} \mathrm{O}_{4} @ \mathrm{mSiO}_{2}$ microspheres in these experiments was $\sim 3.5 \mathrm{kDa}, 1.3$ times higher than for the analysis of BSA digested with trypsin (Table 1). The MW values of the largest identified peptides were also higher, up to $7.55 \mathrm{kDa}$. Moreover, larger peptides generated by Sap9 enabled higher protein sequence coverage from a smaller number of peptides: $80 \%$ of Trastuzumab sequence coverage with a total of 68 peptides was identified from only $33 \mathrm{fmol}(5 \mathrm{ng})$ of the loaded sample. When the sample amount was increased to 333 fmol, $98 \%$ of the antibody sequence coverage was obtained from a total of 229 peptides, indicating also the detection of peptides carrying various modifications (Table SI-5). Therefore, within the respective false discovery error rates, the IgG sequence coverage obtained by SPE-GEMS/MS with a lowresolution mass spectrometer is similar to the one achieved by the nano HPLC-high resolution MS approach from 8 pmol of the antibody digest. ${ }^{27}$

Importantly, peptides containing CDRs were discriminated for both heavy and light chains (Hc and Lc, respectively) of Trastuzumab in all performed experiments and their technical replicates. Examples of CID mass spectra collected from the CDR-containing peptides are shown in Figure 3.

In accordance with the previously reported results, ${ }^{27}$ large peptides containing two CDRs per peptide were also detected (Figure 3a) revealing the CDRs connectivity. Notably, this information is normally lost, when the antibodies are digested with trypsin or other BUP benchmarked proteases like LysC and GluC, ${ }^{27}$ as they generate shorter proteolytic peptides.

Discussed results illustrate the efficiency of SPE-GEMS/MS with $\mathrm{C}_{8}-\mathrm{Fe}_{3} \mathrm{O}_{4} @ \mathrm{mSiO}_{2}$ microspheres for the fast and sensitive structural analysis of Trastuzumab from its Sap9-derived digest within eBUP-based studies. In comparison with the previously reported nano HPLC-based method, ${ }^{27}$ SPE-GEMS/MS provided the possibility to obtain a similar antibody sequence coverage within the respective false discovery error rates 3 times faster and from a much smaller sample amount. Moreover, in comparison with commonly used BUP-based sequencing of monoclonal antibodies by HPLC-MS, ${ }^{38}$ nano HPLC-MS, ${ }^{39}$ and UPLC-MS, ${ }^{40}$ the proposed technique offers a 3-4.5-fold gain in experimental time. The small size of the FMM plug in the SPE-GEMS/MS microchip led to the fast sample loading, purification/preconcentration, fractionation (only $20 \mathrm{~min}$ ), and very short plug regeneration time (1-2 min). The minimized distance between the sorbent chamber and microchip tip emitter (Figure 1a) ensured the minimum dilution of very concentrated eluting peptide fractions and, hence, high sensitivity of the proposed technique. At the same time, the small size of the SPE sorbent plug possesses obvious disadvantages of the limited loading capacity and lower separation quality compared to the nano HPLC column. These disadvantages were successfully overcome by combining two components: (i) $\mathrm{C}_{8}-\mathrm{Fe}_{3} \mathrm{O}_{4} @ \mathrm{mSiO}_{2}$ microspheres as the SPE sorbent with an improved loading capacity and affinity toward large peptides and (ii) Sap9 as an enzyme, digesting the analyte into large peptides, i.e. generating a less complex and more informative peptide mixture. As a result, SPE-GEMS/MS analysis yielded not only high Trastuzumab sequence coverage from a low sample amount but also the detection of all six CDRs, present in this molecule and highly important for its characterization.

As the SPE-GEMS/MS approach combines in one microfluidic device sample preconcentration, purification, and fractionation, it allows omitting an additional sample pretreatment step with Zip-Tip cartridges ${ }^{27}$ or an in-line guard column. $^{38}$ Moreover, as was already mentioned above, the SPE sorbent plug can be easily renewed and the microchip itself can be operated in a disposable manner. Therefore, the proposed microfluidic device could be regarded as a cheap, disposable, and fast alternative to a more expensive traditional precolumn-separation column system ${ }^{27,39}$ for eBUP-based structural analysis of individual proteins in cases which do not require extensive separation of sample components.

Furthermore, the SPE-GEMS/MS system is compatible with various MS instruments. In the current work, the LTQ mass spectrometer was employed, which is a low resolution but fast and sensitive instrument. To improve peptide identification confidence, the proposed technique can be easily coupled with high resolution mass spectrometers, for example, a Q Exactive HF Orbitrap-Fourier Transform (FT)-MS instrument. ${ }^{41}$ In such a configuration, SPE-GEMS/MS also will benefit from the high resolution and high mass accuracy measurements, as the nano HPLC-based approach, which used an Orbitrap Elite FTMS instrument, providing highly confident analyte identification. ${ }^{27}$

Analysis of the IgG Mixture Digested with Sap9. The SPE-GEMS/MS technique was further tested on the analysis of a more complex sample, Sap9-derived digest of six therapeutic monoclonal antibodies (equimolar mixture) corresponding to different IgG subclasses. As the processing of a more complex sample could suffer from the restricted size of the FMM plug, three different sample loading schemes were tried for the Sap9derived digest of the $\operatorname{IgG}$ mixture, in order to increase the analyte sequence coverage. Standard sample loading was used as a first procedure with $10 \mu \mathrm{L}$ of the final injected volume. Then, the waste flowing out of the microchip tip during the sample loading $(\sim 5 \mu \mathrm{L})$ was collected and reinjected to the microfluidic device, providing the second type of sample loading scheme with $\sim 15 \mu \mathrm{L}$ of the final injected volume. For the third loading procedure with an $\sim 20 \mu \mathrm{L}$ final injected volume, the second waste $(\sim 4-5 \mu \mathrm{L})$, arising from the second loading scheme, was further reinjected into the microchip. IgGs sequence coverage values, obtained by SPE-GEMS/MS analysis using the described sample loading procedures, are summarized in Table SI-6.

As was expected, the simple sample loading by the first scheme resulted in the lowest sequence coverage values of 36$60 \%$ for Lc and Hc of mixture components. The second loading scheme, which required 5 min more for the sample injection, yielded on average 1.5 times higher sequence coverage values for Lc and $\mathrm{Hc}$ of antibodies. At the same time, with the third sample loading scheme on average 1.2 times higher sequence coverage was achieved in comparison with the second one but was less reproducible (data not shown) and required twice more time for the sample injection. Therefore, the second sample loading scheme was chosen for the further SPE-GEMS/ MS analysis of the IgG mixture, and other experimental 
parameters were the same as for the analysis of the single Trastuzumab digest. Obtained data are presented in Table 3.

Table 3. SPE-GEMS/MS Analysis of the IgG Mixture Digested with Sap9 ${ }^{b}$

\begin{tabular}{|c|c|c|c|c|}
\hline name & & $\begin{array}{c}\text { sequence } \\
\text { coverage, } \%\end{array}$ & unique peptides, \#* & CDR, \# \\
\hline \multirow[t]{2}{*}{ Adalimumab, IgG1 } & $\mathrm{Lc}$ & $71 \pm 5$ & $9 \pm 1$ & 3 \\
\hline & $\mathrm{Hc}$ & $54 \pm 3$ & $3 \pm 1$ & $2-3$ \\
\hline \multirow{2}{*}{$\begin{array}{l}\text { Bevacizumab, } \\
\text { IgG1 }\end{array}$} & $\mathrm{Lc}$ & $68 \pm 7$ & $4 \pm 1$ & $2-3$ \\
\hline & $\mathrm{Hc}$ & $56 \pm 5$ & $3 \pm 1$ & $1-3$ \\
\hline \multirow{2}{*}{$\begin{array}{l}\text { Trastuzumab, } \\
\text { IgG1 }\end{array}$} & $\mathrm{Lc}$ & $75 \pm 5$ & $7 \pm 1$ & 3 \\
\hline & $\mathrm{Hc}$ & $65 \pm 6$ & $25 \pm 4$ & 3 \\
\hline \multirow[t]{2}{*}{ Natalizumab, IgG4 } & $\mathrm{Lc}$ & $68 \pm 6$ & $5 \pm 2$ & $2-3$ \\
\hline & $\mathrm{Hc}$ & $64 \pm 7$ & $35 \pm 5$ & 3 \\
\hline \multirow{2}{*}{$\begin{array}{l}\text { Panitumumab, } \\
\text { IgG2 }\end{array}$} & $\mathrm{Lc}$ & $51 \pm 7$ & $4 \pm 2$ & $1-2$ \\
\hline & $\mathrm{Hc}$ & $49 \pm 3$ & $28 \pm 6$ & $1-3$ \\
\hline \multirow[t]{2}{*}{ Rituximab, IgG1 } & $\mathrm{Lc}$ & $45 \pm 6$ & $4 \pm 1$ & $1-2$ \\
\hline & $\mathrm{Hc}$ & $60 \pm 4$ & $23 \pm 1$ & $2-3$ \\
\hline $\begin{array}{r}\text { peptide } \mathrm{MW} \\
\text { range, } \mathrm{kDa}\end{array}$ & & $2.1-6.3$ & $\begin{array}{c}\text { peptide average } \\
\text { MW, kDa }\end{array}$ & 3.5 \\
\hline
\end{tabular}

*Total number of unique identified peptides (including the ones carrying various modifications). Sample amount: $333 \mathrm{fmol}(50 \mathrm{ng})$, equimolar mixture; second loading scheme: sample + first waste, $n=3$. ${ }^{b} \mathrm{Hc}-$ heavy chain; Lc - light chain.
As displayed in Table 3, analysis of $333 \mathrm{fmol}$ (50 ng) of the equimolar IgG mixture by SPE-GEMS/MS with the improved sample loading scheme resulted within $\sim 40 \mathrm{~min}$ in the moderate sequence coverage for Lcs and Hcs of mixture components: $45-75$ and $49-68 \%$, respectively. These values are similar to the results obtained with nano HPLC-MS from 8 pmol of the sample with electron transfer dissociation (ETD) fragmentation but lower than the ones acquired with CID and high-energy collision induced dissociation (HCD) fragmentation techniques. ${ }^{27}$

In contrast with the single antibody analysis, the small size of the SPE sorbent plug started altering the achievable sequence coverage for the components of the IgG mixture. Nevertheless, in a single SPE-GEMS/MS run it was possible to rapidly identify all six IgGs, in spite of the incomplete sequence coverage and high sequence homology, especially within the same IgG subclass. Such identification was feasible, as for each antibody large unique peptides, containing CDRs, were efficiently preconcentrated on $\mathrm{C}_{8}-\mathrm{Fe}_{3} \mathrm{O}_{4} @ \mathrm{mSiO}_{2}$ microspheres and further detected, ensuring the discrimination between mixture components. Examples of CID mass spectra collected from the peptides with CDR entities, belonging to the Lcs and Hcs of antibodies, are displayed in Figures 4 and SI-7, respectively.
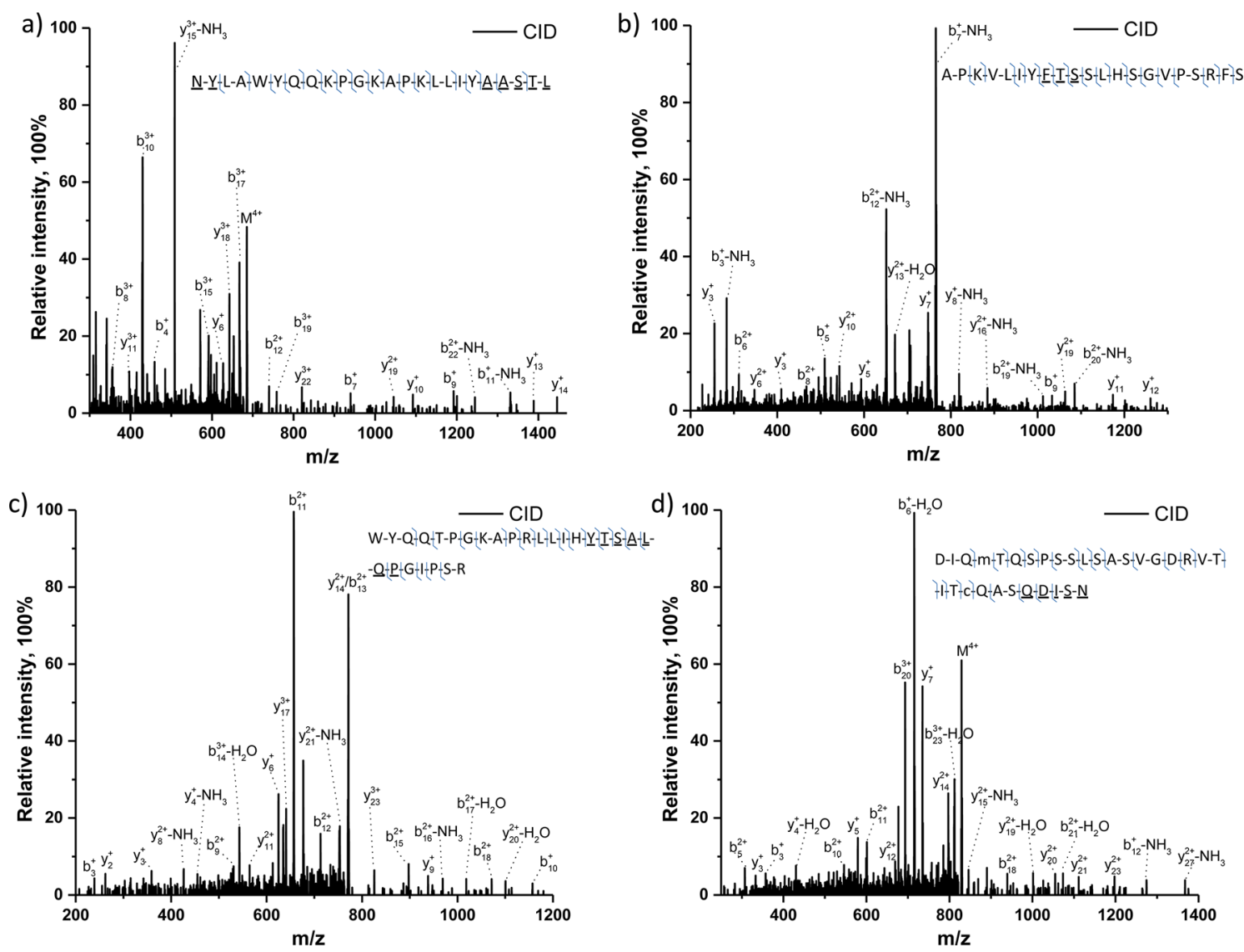

Figure 4. Representative CID mass spectra of CDR-containing peptides with assignments of their respective $b, y$ product ions, identified by SPEGEMS/MS analysis of the antibodies mixture digested with Sap9. Selected peptides derived from Lc of a) Adalimumab, IgG1, with CDRs 1 and 2, MW = 2736.5 Da; b) Bevacizumab, IgG1, with CDR 2, MW = 2292.2 Da; c) Natalizumab, IgG4, with CDR 2, MW = 3077.6 Da; d) Panitumumab, IgG2, with CDR 1, MW = 3311.5 Da. Insets: corresponding peptide sequences with assigned peptide backbone cleavage sites and underlined CDRs. Experimental conditions: $\mathrm{C}_{8}-\mathrm{Fe}_{3} \mathrm{O}_{4} @ \mathrm{mSiO}_{2}$ microspheres as a SPE sorbent, $333 \mathrm{fmol}$ ( $50 \mathrm{ng}$ ) of the sample loaded by second loading scheme (sample + first waste), equimolar mixture. 
Some of the identified unique peptides were carrying adjacent CDRs, for example a peptide derived from the Lc of Adalimumab (Figure 4a). The detection of such peptides not only revealed the information about CDRs connectivity but also could improve the reliability of the appropriate $\operatorname{IgG}$ identification, as some of these molecules share CDRs, even when they do not belong to the same subclass and bind different antigens. ${ }^{27}$ As can be concluded from the presented results, SPE-GEMS/MS could still be suitable not only for the analysis of a single antibody but also their relatively simple mixtures, owing to its speed, sensitivity, and absence of additional sample pretreatment steps. Meanwhile, increased sequence coverage for the IgG mixture components could be obtained by the application of the third sample loading scheme or by creating a SPE-GEMS/MS microchip with a larger sorbent chamber and, hence, sorbent plug. Combination of the proposed microfluidic device with a high resolution MS instrument would also significantly improve performance and accuracy of the SPE-GEMS/MS technique opening the possibility of processing more complex samples within the eBUP approach.

\section{CONCLUSIONS}

On-chip SPE-GEMS/MS analysis with mesoporous $\mathrm{C}_{8}-$ $\mathrm{Fe}_{3} \mathrm{O}_{4} @ \mathrm{mSiO}_{2}$ microspheres as the SPE sorbent was proposed for the fast sample preconcentration/purification, fractionation, and online MS/MS detection. This technique targets fast protein sequencing from a limited sample amount. Due to the properties of mesoporous FMM used as the SPE sorbent, it provides a sensitive identification of large peptides with a MW of $2.5-7 \mathrm{kDa}$ even from a standard tryptic digest, fulfilling the eBUP requirements. Combination of the Sap9-based digestion, generating large proteolytic peptides, with the proposed onchip technique allowed efficient analysis of a single therapeutic IgG Trastuzumab, as well as a mixture of six IgGs, from low sample quantities. Trastuzumab analysis resulted within less than 35 min in 98 and $80 \%$ of its sequence coverage from only 333 and 33 fmol of the sample, respectively. For the IgG mixture, online enrichment and detection of large unique peptides with CDR entities enabled identification of all mixture components despite their high sequence homology.

Sensitivity, speed of the analysis, compatibility with various MS instruments, low cost, and disposable nature of the microchip, together with overall simplicity of the developed assay in combination with Sap9-based digestion, make SPEGEMS/MS suitable for a fast primary structure assessment of therapeutic antibodies from a low sample amount. This technique could be potentially useful for the rapid peptide mapping or CDR screening of biosimilar candidates to reduce the pool of the samples for the next analytical step, consisting of the time-consuming detailed assessment of the IgGs structure. ${ }^{39}$ Moreover, the proposed approach could be applied for rapid structural analysis of isolated proteins and further extended to various eBUP studies, especially being coupled with high resolution MS instruments for the improved accuracy of the analyte identification.

\section{ASSOCIATED CONTENT}

\section{S Supporting Information}

The Supporting Information is available free of charge on the ACS Publications website at DOI: 10.1021/acs.analchem.5b04045.
Details about microchip fabrication procedure, SEM and TEM pictures of $\mathrm{C}_{8}-\mathrm{Fe}_{3} \mathrm{O}_{4} @ \mathrm{mSiO}_{2}$ microspheres, results of model peptide mixture analysis or various sample loading schemes, examples of CID mass spectra, and lists of identified peptides (PDF)

\section{AUTHOR INFORMATION}

\section{Corresponding Author}

*Phone: 41 (0)21 69331 51. Fax: 41 (0)21 69336 67. E-mail: hubert.girault@epfl.ch.

\section{Notes}

The authors declare no competing financial interest.

\section{ACKNOWLEDGMENTS}

The authors would like to thank Dr. Michel Monod for providing the Sap9 protease and Veronique Amstutz for SEM and TEM pictures. The work of K.S. and Y.O.T. was financially supported by the Swiss National Science Foundation (project 200021-147006) and the European Research Council (ERC Starting grant 280271).

\section{REFERENCES}

(1) Selvaraju, S.; Rassi, Z. El. Electrophoresis 2012, 33, 74-88.

(2) Li, X.-S.; Zhu, G.-T.; Luo, Y.-B.; Yuan, B.-F.; Feng, Y.-Q. TrAC, Trends Anal. Chem. 2013, 45, 233-247.

(3) Xie, L.; Jiang, R.; Zhu, F.; Liu, H.; Ouyang, G. Anal. Bioanal. Chem. 2014, 406, 377-399.

(4) Bland, C.; Bellanger, L.; Armengaud, J. J. Proteome Res. 2014, 13, 668-680.

(5) Ji, L.; Wu, J.-H.; Luo, Q.; Li, X.; Zheng, W.; Zhai, G.; Wang, F.; Lu, S.; Feng, Y.-Q.; Liu, J.; Xiong, S. Anal. Chem. 2012, 84, 22842291.

(6) Tan, F.; Zhang, Y.; Mi, W.; Wang, J.; Wei, J.; Cai, Y.; Qian, X. J. Proteome Res. 2008, 7, 1078-1087.

(7) Loo, D.; Jones, A.; Hill, M. M. J. Proteome Res. 2010, 9, 54965500.

(8) Zhao, M.; Xie, Y.; Deng, C.; Zhang, X. J. Chromatogr. A 2014, $1357,182-193$

(9) Chen, L.; Wang, T.; Tong, J. TrAC, Trends Anal. Chem. 2011, 30, $1095-1108$

(10) Lin, J.-H.; Wu, Z.-H.; Tseng, W.-L. Anal. Methods 2010, 2, 1874-2056.

(11) Baumann, S.; Ceglarek, U.; Fiedler, G. M.; Lembcke, J.; Leichtle, A.; Thiery, J. Clin. Chem. 2005, 51, 973-980.

(12) Yao, N.; Chen, H.; Lin, H.; Deng, C.; Zhang, X. J. Chromatogr. A 2008, 1185, 93-101.

(13) Chen, H.; Liu, S.; Li, Y.; Deng, C.; Zhang, X.; Yang, P. Proteomics 2011, 11, 890-897.

(14) Han, E. C.; Lee, Y.-S.; Liu, Y.-C.; Liao, H.-Y.; Liao, W.-S.; Lai, H.-C.; Peng, C.-Y.; Jeng, L.-B. Clin. Chim. Acta 2011, 412, 2174-2182.

(15) De Noo, M. E.; Tollenaar, R. A. E. M.; Özalp, A.; Kuppen, P. J. K.; Bladergroeen, M. R.; Eilers, P. H. C.; Deelder, A. M. Anal. Chem. 2005, 77, 7232-7241.

(16) Chen, H.; Xu, X.; Yao, N.; Deng, C.; Li, Y.; Yang, P.; Zhang, X. Proteomics 2008, 8, 2778-2784.

(17) Chen, H.; Deng, C.; Li, Y.; Dai, Y.; Yang, P.; Zhang, X. Adv. Mater. 2009, 21, 2200-2205.

(18) Sun, L.; Zhao, Q.; Zhu, G.; Zhou, Y.; Wang, T.; Schan, Y.; Yang, K.; Liang, Z.; Zhang, L.; Zhang, Y. Rapid Commun. Mass Spectrom. 2011, 25, 1257-1265.

(19) Liu, S.; Li, Y.; Deng, C.; Mao, Y.; Zhang, X.; Yang, P. Proteomics 2011, 11, 4503-4513.

(20) Zhao, L.; Qin, H.; Wu, R.; Zou, H. J. Chromatogr. A 2012, 1228, 193-204. 
(21) Jonker, N.; Kretschmer, A.; Kool, J.; Fernandez, A.; Kloos, D.; Krabbe, J. G.; Lingeman, H.; Irth, H. Anal. Chem. 2009, 81, 42634270.

(22) Ramautar, R; de Jong, G. J.; Somsen, G. W. Electrophoresis

2012, 33, 243-250.

(23) Ramautar, R.; Somsen, G. W.; de Jong, G. J. Electrophoresis 2014, 35, 128-137.

(24) Laskay, Ü. A.; Lobas, A. A.; Srzentić, K.; Gorshkov, M. V.; Tsybin, Y. O. J. Proteome Res. 2013, 12, 5558-5569.

(25) Laskay, Ü. A.; Srzentić, K.; Monod, M.; Tsybin, Y. O. J. Proteomics 2014, 110, 20-31.

(26) Gasilova, N.; Qiao, L.; Momotenko, D.; Pourhaghighi, M. R.; Girault, H. H. Anal. Chem. 2013, 85, 6254-6263.

(27) Srzentic, K.; Fornelli, L.; Laskay, Ü. A.; Monod, M.; Beck, A.; Ayoub, D.; Tsybin, Y. O. Anal. Chem. 2014, 86, 9945-9953.

(28) Albrecht, A.; Felk, A.; Pichova, I.; Naglik, J. R.; Schaller, M.; De Groot, P.; MacCallum, D.; Odds, F. C.; Schäfer, W.; Klis, F.; Monod, M.; Hube, B. J. Biol. Chem. 2006, 281, 688-694.

(29) Deutsch, E. W.; Mendoza, L.; Shteynberg, D.; Farrah, T.; Lam, H.; Tasman, N.; Sun, Z.; Nilsson, E.; Pratt, B.; Prazen, B.; Eng, J. K.; Martin, D. B.; Nesvizhskii, A. I.; Aebersold, R. Proteomics 2010, 10, $1150-1159$.

(30) Second, T. P.; Blethrow, J. D.; Schwartz, J. C.; Merrihew, G. E.; Maccoss, M. J.; Swaney, D. L.; Russell, J. D.; Coon, J. J.; Zabrouskov, V. Anal. Chem. 2009, 81, 7757-7765.

(31) Chen, H.; Liu, S.; Yang, H.; Mao, Y.; Deng, C.; Zhang, X.; Yang, P. Proteomics 2010, 10, 930-939.

(32) Pelzing, M.; Neusü $\beta$, C. Electrophoresis 2005, 26, 2717-2728.

(33) Noga, M.; Sucharski, F.; Suder, P.; Silberring, J. J. Sep. Sci. 2007, 30, 2179-2189.

(34) Freeke, J.; Barattini, V.; Sneekes, E.-J.; Milton, D.; Adams, S.; Swart, R.; Pereira, L. 2011. http://www.thermoscientific.com/ content/dam/tfs/ATG/CMD/CMD\%20Documents/posters/POPSCCS-1211-0811-Development-Reliability-Testing-Protocols-EN.pdf (accessed Jan 1, 2016).

(35) Liu, Q.; Cobb, J. S.; Johnson, J. L.; Wang, Q.; Agar, J. N. J. Chromatogr. Sci. 2014, 52, 120-127.

(36) Winter, D.; Pipkorn, R.; Lehmann, W. D. J. Sep. Sci. 2009, 32, 1111-1119.

(37) Rozenbrand, J.; de Jong, G.; van Bennekom, W. P. J. Sep. Sci. 2011, 34, 2199-2205.

(38) Manuilov, A. V.; Radziejewski, C. H.; Lee, D. H. mAbs 2011, 3, 387-395.

(39) Ayoub, D.; Jabs, W.; Resemann, A.; Evers, W.; Evans, C.; Main, L.; Baessmann, C.; Wagner-Rousset, E.; Suckau, D.; Beck, A. $m A$ ss 2013, 5, 699-710.

(40) Diepold, K.; Bomans, K.; Wiedmann, M.; Zimmermann, B.; Petzold, A.; Schlothauer, T.; Mueller, R.; Moritz, B.; Stracke, J. O.; Molhoj, M.; Reusch, D.; Bulau, P. PLoS One 2012, 7, e30295.

(41) Scheltema, R. A.; Hauschild, J.-P.; Lange, O.; Hornburg, D.; Denisov, E.; Damoc, E.; Kuehn, A.; Makarov, A.; Mann, M. Mol. Cell. Proteomics 2014, 13, 3698-3708. 